\title{
Do Parental Coping, Involvement, Religiosity, and Racial Identity Mediate Children's Psychological Adjustment to Sickle Cell Disease?
}

\author{
Oscar A. Barbarin \\ University of Michigan
}

\begin{abstract}
Many African Americans with sickle cell disease (SCD) also experience significant economic hardship. Yet, few studies of the psychosocial effects of SCD employ designs robust enough to control socioeconomic factors. This study compares the functioning of families with SCD to that of healthy controls matched for race and socioeconomic status. In general, functioning within SCD and control families did not differ. However, parents granted less autonomy to, and were less involved in the schooling of, children with SCD. Overall, SCD had a greater impact on children's social and academic competence than on their emotional functioning. However, adolescents with SCD and their siblings were at greater risk for mental health difficulties than were controls. The more SCD interfered with living normally, the greater the risk of psychological dysfunction. Importantly, emotional well-being in parents moderated the adverse effects of SCD on children. Similarly, racial consciousness, religiosity, and emotional support enhanced parental coping.
\end{abstract}

The social and physical strains associated with chronic childhood diseases often have been noted in the clinical records of pediatric health care settings. These notes often reflect concerns about developmental impairments that

AUTHOR'S NOTE: The University of Michigan Family Development Project study of adjustment to sickle cell disease was made possible by a the generous support of the National Institute of Child Health and Human Development (Grant R01 HD23968). Gratitude is expressed to the families who generously gave of their time. Special thanks are given to Mary Ortega, who served as assistant director of the project, and to the many students in psychology and social work associated over the 5-year period of the study. Without their dedication and talents, this research would not have been possible.

JOURNAL OF BLACK PSYCHOLOGY, Vol. 25 No. 3, August 1999 391-426

(C) 1999 The Association of Black Psychologists 
range from demoralization, excessive dependence, and social immaturity to negative self-concept, school difficulties, and psychological maladjustment (Barbarin, 1990). As family paradigms have gained wide acceptance in pediatric circles, parallel concerns have arisen about the effects of illness on the way in which families function as units, with the greatest concern directed at the previously ignored sibling subsystem (Barbarin et al., 1995). Due to the efforts of an increasing number of researchers from many disciplines, we now understand a great deal about the fundamental problems of psychosocial adjustment faced by children with sickle cell disease and their families (Whitten \& Nishiura, 1985). Empirical studies regarding the impact of sickle cell disease (SCD) have been done in a number of domains that include mental health (Yang, Cepeda, Price, Shah, \& Mankad, 1994), academic achievement, neuropsychological functioning (Wasserman, Wilimas, Fairclough, Mulhern, \& Wang, 1991), social competence, and social maturity (Noll et al., 1996).

\section{CRITIQUE OF RESEARCH ON}

\section{ADJUSTMENT OUTCOMES IN SCD}

The soundness of claims about adverse psychological consequences of SCD may be viewed with skepticism due to two shortcomings. First, inconsistent findings across studies, small effect sizes, and weak explanations make it difficult to develop convincing models linking child outcomes to SCD. Frequently, this results from studies that limit their search to the main effects of SCD and ignore the influences of other critical factors that undoubtedly moderate the impact of the disease on functioning (Kliewer \& Lewis, 1995; Lewis \& Kliewer, 1996). The second shortcoming is related conceptually and practically to the first. Studies of children with SCD in the United States are studies of African American children. Yet, until recently, most have failed to position this work within a broader context of research on race, economic hardship, and psychosocial functioning (Sterling, Peterson, \& Weekes, 1997).

Moreover, by omitting a race-matched control group, the earliest studies often carried out in pediatric settings implied that no other conditions need to be accounted for in drawing inferences about the impact of SCD on children's social, emotional, and academic adjustment. So, for example, below gradelevel academic performance and neurological deficits were attributed to SCD and not to economic disadvantage and its sequelae such as poor nutrition, racial inequality in schools, and social oppression (Richard \& Burlew, 1997). This problem is compounded by an apparent lack of familiarity with research that shows similar trends in academic and psychological functioning of 
healthy African American children as those observed among African Americans with SCD (Barbarin \& Soler, 1993; Frederick D. Patterson Research Institute, 1997; McLoyd, 1998).

Consequently, studies that assert a relation between SCD and behavioral functioning, emotional problems, and compromised neurological functioning are open to challenge when they fail to control for a plausible alternative explanation of their findings. Principal among these moderators are illnessrelated stressors and life change, individual and family coping, and access to social and cultural resources in dealing with illness.

\section{STRESS, COPING, AND FAMILY FUNCTIONING AS MEDIATORS OF OUTCOME AMONG AFRICAN AMERICANS WITH SCD}

Chronic illness is an ongoing series of stressors whose high demands on the capacity to cope have the potential of impeding healthy social and emotional development. For economically disadvantaged families, these are not the only issues that place demands on the coping resources of individuals and families. Illness is one of many hardships. Thus, having a serious, chronic, life-threatening illness contributes to the already heavy burdens borne by Black children and their families.

\section{INDIVIDUAL COPING AND ADJUSTMENT: MEDIATOR OF STRESS}

Adoption of a coping style is strongly influenced by the perceived predictability, controllability, and severity of the stress (Menaghan, 1983). Situations in which the individual lacks adequate information about stressors and those over which the individual has control are associated with the use of a direct action style. Situations in which the primary stressor is health related or in which the individual lacks control are associated with emotion-focused and cognitive reappraisal styles. It should be noted that these styles are not completely independent. Styles aimed at changing oneself or one's situation also may contribute to emotional management.

\section{IMPORTANCE OF FAMILY FUNCTIONING}

The quality of family life is considered an important factor moderating the potentially negative impact of these psychosocial stressors on developmental outcomes. When a family functions well, it may imbue the child with a sense 
of mastery by providing opportunities through which the child can experience success, maintain a sense of purpose, and develop conviction about personal efficacy and autonomy. Moreover, an effectively functioning family can help a child to consolidate a favorable personal and racial identity, foster commitment to achievement, nurture a sense of responsibility, and prepare to assume adult roles in work and marriage in spite of a less than accommodating social environment. This is a particularly complex but cogent issue for children with a chronic, life-threatening illness whose survival into adulthood might be in question. We have only limited information about how families deal with the task of socializing and preparing ill or healthy children for adult life, and we are not clear about the role of sociocultural variables in their functioning.

\section{RESEARCH AIMS}

This research examines the effects of chronic illness on the socioemotional development of African American children and the extent to which family life and coping mediate the expected adverse outcomes. It delineates the stressors associated with chronic illness, its impact on children's lives, and the resulting quality of their psychological functioning. Specifically, this report tests a set of relationships predicted by a model of Black family functioning (Barbarin, 1983). Figure 1 depicts the primary elements of this model that are relevant to this research report. It proposes a set of relationships among stress, family life, coping, and developmental outcomes for ill children. For many African American families, illness is one of many stressors that they encounter, and it should not be assumed that it is the most troublesome. This is particularly true for families of poor and low socioeconomic status. The illness and its impact on life combined with the effects of socioeconomic disadvantages can have an effect on parental well-being (McLoyd, 1998). This in turn can influence how effectively the family functions and, more specifically, how well parents function, particularly in regard to supporting the child and involving themselves in the child's academic life. In this model, sociocultural factors such as religiosity, racial identity, and racial attributions influence family coping, problem solving, communication, and relations. They shape how Black families perceive, act, and respond emotionally to life's stressors and, in particular, to the demands of a serious chronic illness. In turn, these patterns of family functioning mediate the effects of illness-related stress on developmental outcomes of seriously ill children. 


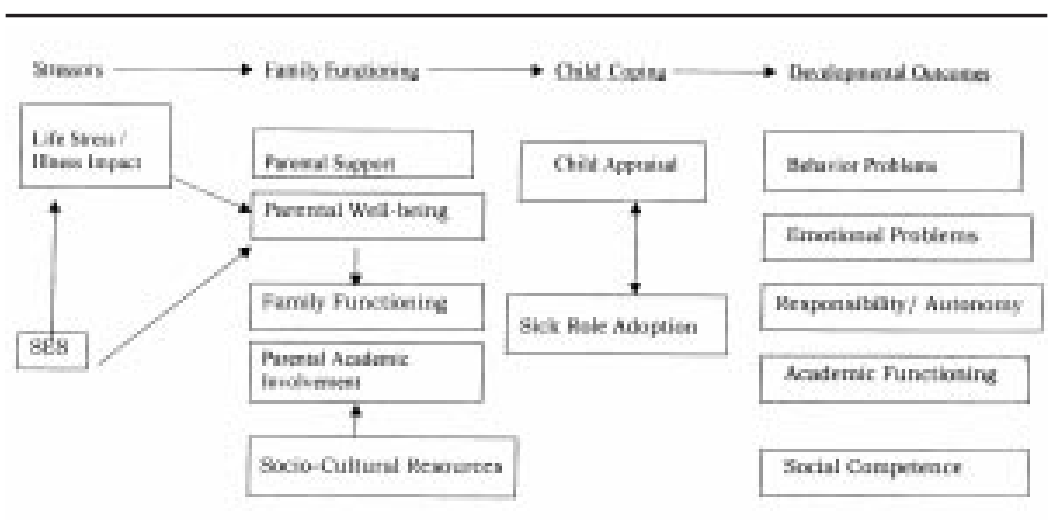

Figure 1: Model of Illness, Family Functioning, and Development in African Americans With Sickle Cell Disease

NOTE: SES = socioeconomic status.

\section{RESEARCH QUESTIONS}

Are African-American children, adolescents, and parents whose lives are affected by SCD worse off than African Americans whose lives are not affected by the disease? Does SCD impair, enhance, or otherwise affect functioning of children, adolescents, and their parents? If it does, then in what domains are these effects most pronounced? Are they limited to individual psychological functioning, and do they imply psychological differences among children and parents that are a consequence of heightened levels of stress presumably associated with SCD? Does impairment occur in domains such as academic functioning or in styles of parental socialization such as the promotion of child autonomy and maturity? For example, are parents of children and adolescents with SCD more likely to overprotect and infantilize the child and less likely to encourage the children to assume maturity-enhancing responsibility and decision making about the mundane aspects of their lives? Are there effects observed in other aspects of family relationships such as the degree of social support and the level of conflict?

\section{EXPECTED FINDINGS}

This article describes the illness-related stress reported by African American children with SCD and their relationship to socioemotional functioning. 
If the existing body of literature is correct, then the adverse psychological impact of SCD should be reflected in higher levels of anxiety and depression, and children also would be described by their parents as having more problems than either healthy children or siblings. This work not only replicates previous research that identifies the adverse sequelae of illness but also assesses the extent to which illness sequelae are moderated by family relationships and functioning and the psychological health of primary caregivers. Moreover, sociocultural variables identified by Barbarin (1983) were thought to moderate the adverse impact of illness-related stressors on developmental outcomes. The nature and extent of adverse emotional outcomes of illness were expected to be moderated by family functioning, the availability of sociocultural resources such as parental religiosity, a firm racial identity, and extended family and social support networks. In addition, supportive, collaborative, and involved parenting styles that encourage an ageappropriate independence in children also were thought to moderate the effects of illness. Effective family functioning imbues a child with a sense of mastery and purpose, and a conviction about personal efficacy and autonomy. Moreover, an effectively functioning family can help a child to consolidate a favorable personal and racial identity, foster commitment to achievement, nurture a sense of responsibility, and prepare to assume adult roles in work and marriage in spite of a less than accommodating social environment. This is a complex but cogent issue, particularly for children with a chronic, life-threatening illness whose survival into adulthood might be in question.

\section{METHOD}

\section{PARTICIPANTS}

Child participants in the study consisted of children with SCD $(n=77)$, siblings of children with SCD $(n=28)$, and children who had neither an illness nor siblings with an illness $(n=74)$.

Children with SCD and their siblings were selected from the roster of all 5- to 18-year-old children participating in a statewide Michigan sickle cell program. Because the refusal rate was less than $10 \%$, children are considered a representative sample of those actively enrolled in the treatment at comprehensive SCD centers. 
Non-ill comparison or control children were recruited with the goal of matching the SCD participants on race, age, gender, mother's marital status, and socioeconomic status. Inferences about the effects of illness can be drawn from comparisons of the functioning of ill children to that of their healthy siblings and a matched group of non-ill children. Children for this comparison group were recruited through nominations of friends made by the ill children, advertising in neighborhoods, and public schools serving economically diverse communities.

\section{PROCEDURES}

Families that participated were offered $\$ 35$ for each visit for their time to do the interviews and complete questionnaires. Data collection required 2 to 3 hours and two visits to complete. Teams of trained interviewers (graduate students in psychology and social work) conducted interviews in the respondents' homes. Informed consent and permission to audiotape interviews were obtained in a family group session before starting.

Data collection began with a family interview that focused on the role of the child in the family; family strategies for managing medical care; the impact of the illness; critical illness-related events and tasks; significant stressful life events; coping styles and strategies used to deal with these events; the nature of available social support; relationships with extended family, school, and medical staff; self-evaluation of coping effectiveness; racial identity; religious faith and practices; and demographic characteristics.

\section{INDIVIDUAL PARENT ASSESSMENT: INTERVIEWS}

Semistructured interviews were conducted with parents. Topics covered were illness-related stress, coping, social support, involvement in the mundane aspects of the child's life and school, mental health functioning, family functioning, life satisfaction, Black identity, and religiosity. The latter two constructs were assessed by means previously tested and standardized in a national study of Black Americans conducted by the Survey Research Center at the University of Michigan's Institute for Social Research (Jackson, Gurin, Hatcher, \& Bowen, 1979). The scales have been derived and validated through confirmatory factor analytic procedures.

- Religiosity assesses the expression of religious beliefs. Respondents indicate the frequency with which they engage in religious practices such as praying, at- 
tending services, singing, tuning into religious programs, and the extent of their religiosity.

- Racial Identity refers to the extent to which respondents label themselves as, identify with, and feel allegiance to Blacks or Americans of African origin and consider it important to instill racial identity in their children. In addition, it refers to behavioral expression of racial cohesion in terms of voting for Black candidates, shopping in Black-owned stores, and using African names.

- Racial Attribution assesses the extent to which respondents attribute outcomes in their lives to their race, discrimination, and Whites keeping Blacks down.

In addition to the personal interviews, parents also completed structured questionnaires on related topics including the following.

The Mental Health Inventory (MHI) (Veit \& Ware, 1983) is a reliable and well-validated, structured questionnaire covering important aspects of mental health functioning. Its validity is supported by factor analysis, and the scales are hierarchical. The MHI is a total score summarizing responses to all scale items and is scored in a direction that indicates favorable psychological adjustment.

The Psychological Distress Scale is a score that summarizes all the symptoms of psychological disorders in the MHI such as anxiety, depression, and loss of control:

- Anxiety refers to feelings of extreme tension, stress, concern, nervousness, preoccupation, worry, and restlessness. It is an inability to relax or settle down. Sometimes, it includes fears and/or physiological reactions such as ulcers, upset stomach, headache, trembling, rashes or itching, heart palpitations, and the feeling that one is about to "explode."

- Depression is a psychological state characterized by sadness, hopelessness, and loss of humor and optimism about the future. It also may by associated with passivity, inability to concentrate or to get going or follow through on things, social withdrawal, a sense of loss, and disturbance of an individual's sleeping and eating patterns.

- Loss of Control refers to the inability to function normally or to exercise usual control over thoughts, behavior, and expression of emotions. It is characterized by emotional fragility, unpredictable or unstable behavioral instability and feeling close to a breaking point, and inability to manage oneself and one's feelings. In an extreme form, it may be accompanied by periods of uncontrollable crying or thoughts of suicide.

The Psychological Well-Being Scale is an indicator of positive mental health that is obtained by summarizing items that make up the general positive affect, social ties, and social desirability subscales: 
- General Positive Affect refers to zest in life, personal feelings of happiness, contentment with self, and a sense of enthusiasm and joy within work and family life.

- Social ties assesses the extent to which an individual feels emotionally connected to and cared for by others.

- Social Desirability assesses a willingness to admit to what might appear to be undesirable or negative thoughts, feelings, or actions. It is associated with the desire to be seen by others in a positive or favorable light and a reluctance to admit to socially disapproved behaviors or negative feelings.

Social Competence/Coping subscales (Pearlin \& Schooler, 1978) assesses the beliefs that individuals have about their own self-worth and efficacy. They provide a window to the worldviews that underlie people's efforts to deal with hardship and to cope with life stress:

- Personal Mastery is an indicator of self-efficacy or the extent to which an individual feels that the person has control over and is responsible for what happens to him or her. It also includes the belief that personal efforts to do something will pay off and that one's actions can make a difference.

- Perceived Helplessness refers to the conviction that one lacks fundamental control in life and that efforts to improve one's conditions do not matter and ultimately will be fruitless.

- Self-Criticism is the tendency to blame oneself, to denigrate one's actions, to disparage one's ability, and to compare oneself to others in a negative way.

- Positive Evaluation refers to self-esteem or the tendency to evaluate oneself in a positive way or to view one's abilities, personal attributes, and accomplishments in a favorable light. Persons with high self-esteem think well of themselves and feel good about who they are.

The Family Relations Scale (Barbarin, 1996) is a multidimensional selfreport instrument that is used to assess clinically relevant aspects of family functioning:

- Differentiation refers to the degree of emotional closeness and the extent to which family members have common attitudes, feelings, and reactions. This subscale assesses the extent to which family members experience the emotions of other family members as their own, interrupt or speak for one another, and observe rules that establish family hierarchy and govern family role performance $(\alpha=.84)$.

- Support refers to an exchange among family members of affection, kindness, and concrete assistance. This subscale assesses the degree of attachment and expression of affection that characterize family relationships $(\alpha=.84)$. 
- Conflict assesses the extent to which disagreements, hostilities and violence exist and are expressed among family members ( $\alpha$ 's $=.76$ to .85 ).

- Organization assesses the extent to which a family values cleanliness, planning ahead, punctuality, and order in maintaining the household ( $\alpha$ 's = .74 to .79).

- Hierarchy assesses a form of control characterized by coercion and unilateral decision making. High scores suggest a great reliance on aversive methods of control and strict enforcement of rules ( $\alpha$ 's $=.40$ to .69 ).

- Expressiveness assesses the extent to which family members share their positive or negative feelings, or their problems and concerns, with one another. High scores suggest that family members readily express their opinions and are open with one another ( $\alpha$ 's $=.77$ to .86$)$.

\section{CHILD ASSESSMENT: INTERVIEWS}

Semistructured individual interviews were conducted with children in their homes. To increase comfort and familiarity on the part of the children or adolescents, interviews were conducted after interviews with the entire family. On average, they lasted about 45 minutes but tended to last much longer with adolescents. Children were asked about illness-related stressors commonly reported with SCD such as pain episodes, bed-wetting, ulcers, and moodiness. They discussed ways in which SCD affected their lives and the attributions they made, if any, about the causes of SCD.

Children also were asked about social support from parents, siblings, and friends as well as the extent to which they exercised autonomy or collaborated with parents in making decisions about important and mundane aspects of their lives. To assess the degree of autonomy in their lives, children were presented with domains and asked to indicate whether decisions were made just by them, mostly by them, together with parents (collaboration), mostly by parents, or just by parents. Examples of domains include decisions related to food they ate, school attendance, leisure activities, clothing and hairstyle, and how time and money are spent.

In addition to the percentage of children responding in each category, three scores were developed from this set of questions: Child Autonomy, the sum of domains in which the child responded just me or mostly me; Collaboration, the sum of domains in which the child responded my parents and I together; and Parental Control, the sum of domains in which the child responded just my parents or mostly my parents. An identical set of items and a parallel procedure are used with parents to derive similar scores.

The Children's Depression Inventory (CDI) is a standardized measure containing 27 items that tap some dimension of depression in children. For each item, the child selects one of three statements that most closely 
describes his or her feelings during the previous 2 weeks. Evidence supporting the scale's validity and reliability are reported by Kovacs (1985).

The Revised Children's Manifest Anxiety Scale is a 37-item standardized measure of anxiety in children. The validity and reliability ( $\alpha$ 's $=.77$ to .86$)$ of the scale have been established (Reynolds \& Richmond, 1978). A 9-item Lie Scale is included. The scale is appropriate for children in Grades 1 to 12. Items are answered with a yes/no format and may be read aloud to younger children.

The Behavior Problem Index (BPI) (Zill, 1985) was developed for the National Health Interview Survey and used as an index of significant behavioral problems with clinical cutoff scores (total raw scores of 14, or 90th percentile) that effectively differentiated children referred and children not referred for mental health services. The evidence supporting the construct validity and reliability of the BPI subscales is substantial (Peterson \& Zill, 1986; Zill, $1985)(\alpha=.85)$. Subscales for the BPI were developed using a principal components analysis of items. Three of the five subscales were used in the present study:

- Antisocial Behavior refers to serious problems of conduct often associated with delinquency such as aggression, stealing, and dishonesty.

- Oppositional Behavior assesses treated disposition, best characterized as difficult to control and influence. Scores indicate the extent to which the child is noncompliant and exhibits difficulty with respect to behavioral self-regulation such as stubbornness, strong temper, and disobedience.

- Social Problems measures social withdrawal and problems in peer and other social relations such as shyness, low peer acceptance, and inability to get along with other children.

The Child Behavior Checklist (CBCL) (Achenbach, 1991) is a parent report measure of child functioning. The problem scale scores are derived from 113 symptoms rated by parents on a 3 -point scale $(0=$ not true, $1=$ sometimes true, $3=$ often true). It yields a Total Problem Index and several subscales. The subscales are based on a dimensional approach to conceptualizing child psychopathology that postulates to primary dimensionsinternalizing and externalizing disorders. The Internalizing Disorders score is the sum of symptoms falling on the anxious-depressed, shy-withdrawn, and somatic complaints factors. The Externalizing Disorders score is the sum of symptoms loading on the delinquent and aggressive behavior factors.

The CBCL balances a decidedly negative emphasis on deficits in child functioning with an asset assessment under the rubric of social competence. Social competence is composed of 20 items that are combined to yield a total score and three subscale scores: Activities, involvement and skill level in 
sports, work, and other activities; Social, organizational memberships, the extensiveness of friendship networks, and the capacity to get along with others; and School, academic grades, success, and problems. Standardized $T$-scores are computed for all scales that permit comparison to national norms. Reliabilities for item scores computed across 1-week intervals and across different interviewers are above .90 .

Questionnaires initially were read to all respondents. Respondents 10 years of age or over initially read along with the interviewer. As it became clearer that respondents could and preferred to read and complete the questionnaires on their own, respondents were permitted to do so in the presence of the interviewer, who answered questions and resolved ambiguities. Items were read to all children under 10 years of age. Debriefing occurred at the end of each data-gathering session. Family members were asked to discuss their reactions to the questions and whether anything was bothering them as a result of the interview or questionnaire. They were given the names and telephone numbers of people to contact if they became upset or despondent later. Most described the interviews as enlightening and helpful in giving them a chance to talk about things that were on their minds. In cases where significant problems were revealed, discussion ensued about what could be done about them and referrals were made to services available at the treatment center or a public social service or mental health facility.

\section{RESULTS}

\section{ILLNESS AND DISTRESS}

This project explored the nature of stress associated with chronic illness through inquiries about the occurrence of medical and other stressors in the lives of ill and non-ill children. Table 1 presents a list of physical problems commonly associated with SCD such as nocturnal enuresis (i.e., bedwetting), strokes, and pain episodes. It also includes psychological and psychophysiological symptoms that might not be unique to the illness but can be markers of distress such as moodiness, sleep problems, fatigue, and a desire to be left alone. The frequencies are presented for each of these stressors for SCD and control children. Because age influences the expected frequency of these problems, data are reported separately for children and adolescents (12 years of age or over). For each age group, chi-square analyses tested differences between SCD and control participants. 
TABLE 1

Percentages of Ill and Control Children and Adolescents Reporting Problems Identified as Sequelae of SCD

\begin{tabular}{|c|c|c|c|c|c|c|}
\hline & \multicolumn{2}{|c|}{ Children } & \multirow[b]{2}{*}{$\chi^{2}$} & \multicolumn{2}{|c|}{ Adolescents } & \multirow[b]{2}{*}{$\chi^{2}$} \\
\hline & $\begin{array}{c}S C D \\
(\mathrm{n}=40)\end{array}$ & $\begin{array}{l}\text { Control } \\
(\mathrm{n}=60)\end{array}$ & & $\begin{array}{c}S C D \\
(\mathrm{n}=37)\end{array}$ & $\begin{array}{l}\text { Control } \\
(\mathrm{n}=30)\end{array}$ & \\
\hline Pain episodes & 71 & 47 & $4.5^{*}$ & 83 & 71 & \\
\hline Fatigue & 68 & 45 & $4.0^{*}$ & 67 & 29 & $7.2 * *$ \\
\hline Nocturnal enuresis & 58 & 40 & & 37 & 5 & $7.0 * *$ \\
\hline Low weight & 23 & 23 & & 51 & 19 & $5.8 *$ \\
\hline Sleep problem & 62 & 36 & $6.0^{* *}$ & 57 & 48 & \\
\hline Bad mood & 59 & 70 & & 49 & 76 & $4.2 *$ \\
\hline Irritability & 31 & 36 & & 41 & 86 & $11.1^{* *}$ \\
\hline Strokes & 10 & 6 & & 17 & 5 & \\
\hline
\end{tabular}

NOTE: SCD = sickle cell disease.

$* p<.05 . * * p<.01$.

Pain episodes, the signature symptom of SCD, were reported at very high rates. In all, $77 \%$ of children reported pain episodes. The expected difference between SCD and control children was observed among younger children but not among adolescents. However, fatigue occurred at high rates, and it significantly distinguished children and adolescents with SCD from their healthy counterparts. Young children with SCD reported significantly more sleep disturbances than did controls. However, adolescence seemed to be the period in which SCD was especially challenging in that youth with SCD experienced particular sources of distress at significantly higher rates than did controls. For example, adolescents were seven times more likely than control children to wet their beds. They also were significantly more likely to experience physical sequelae such as low weight and stunting and psychological symptoms such as irritability and moodiness.

Table 2 presents the impact of events on life. Healthy children were asked to identify and report the impact of major negative life events. The most important aspect of the findings in this table is that the majority of SCD children and adolescents reported impact. For participants with SCD, areas most commonly affected were activities in which they participated and issues possibly related to stigma and infantalization such as the way in which they are treated by family and friends. Although the absolute frequencies were different for children and adolescents, the rank orders of items were close to the same. Interestingly, where differences existed between SCD and control 
TABLE 2

Percentages of Children and Adolescents Reporting Illness Impact on Aspects of Life

\begin{tabular}{|c|c|c|c|c|c|c|}
\hline & \multicolumn{2}{|c|}{ Children } & \multirow[b]{2}{*}{$\chi^{2}$} & \multicolumn{2}{|c|}{ Adolescents } & \multirow[b]{2}{*}{$\chi^{2}$} \\
\hline & $S C D$ & Control & & $S C D$ & Control & \\
\hline Activities you participate in & 45 & 83 & n.s. & 35 & 63 & n.s. \\
\hline Way friends treat you & 39 & 51 & n.s. & 27 & 55 & $5.4^{*}$ \\
\hline Way family treats you & 36 & 37 & n.s. & 16 & 48 & $7.9 * *$ \\
\hline Things you do to have & & & n.s. & & & \\
\hline a good time & 36 & 38 & n.s. & 27 & 66 & $9.8^{* *}$ \\
\hline Future goals and expectations & 31 & 39 & n.s. & 27 & 66 & $9.8 * *$ \\
\hline What is important in life & 31 & 36 & n.s. & 8 & 66 & $24.0 * * *$ \\
\hline Grades & 19 & 64 & $15.7 * * *$ & 43 & 81 & $7.2 * *$ \\
\hline Your personality & 18 & 39 & $4.9 *$ & 16 & 76 & $23.0 * * *$ \\
\hline Way you treat friends & 26 & 46 & $4.0 *$ & 19 & 72 & $19.0 * * *$ \\
\hline
\end{tabular}

NOTE: $\mathrm{SCD}=$ sickle cell disease; n.s. = not significant.

$* p<.05 . * * p<.01 . * * * p<.001$.

participants, the controls reported a life impact of stressful events more often than did SCD children.

Table 3 presents raw score data on parental psychological functioning based on the MHI. Inspection of the means for the subscale scores reveals no overall differences in total mental health functioning for parents of SCD and control children. Similarly, differences on the cumulative MHI are not significant. However, parents of children with SCD are significantly higher on psychological well-being and lower on psychological distress than are parents of control children. They also have significantly higher positive affect and lower levels of problems of self-control and anxiety. Figure 2 presents standard scores for MHI subscales for parents of SCD and control children. This permits absolute comparison of this sample of African American parents to a national sample of adults in the United States. If a standard score of 60 is used as a clinical cutoff, then Figure 2 shows that both groups fall within the nonclinical range on all the dimensions except depression. Therefore, although the two groups do not differ significantly from one another on depression, they do differ from the normative population. This suggests that factors other than SCD might be at play in producing these elevations in depression and many other health indicators where African Americans seem to fare poorly.

Differences between mothers and fathers in the two groups on mental health outcomes derived from the MHI are depicted in Figures 3, 4, and 5. 
TABLE 3

Means, Standard Deviations, and $t$ Values Comparing Mental Health Inventory Scores for Parents of SCD and Control Children

\begin{tabular}{|c|c|c|c|c|c|}
\hline & \multicolumn{2}{|c|}{$\begin{array}{c}S C D \\
(\mathrm{n}=71)\end{array}$} & \multicolumn{2}{|c|}{$\begin{array}{c}\text { Control } \\
(\mathrm{n}=50)\end{array}$} & \multirow[b]{2}{*}{ t Value } \\
\hline & Mean & SD & Mean & $\mathrm{SD}$ & \\
\hline Anxiety & 18.27 & 7.3 & 22.16 & 8.7 & $2.6 * *$ \\
\hline Depression & 16.24 & 2.7 & 15.42 & 3.3 & 1.5 \\
\hline Self-control & 16.02 & 6.3 & 19.22 & 6.5 & $2.7 * *$ \\
\hline General positive affect & 46.04 & 8.1 & 43.34 & 6.6 & $2.0 *$ \\
\hline Social ties & 9.14 & 2.4 & 8.30 & 2.8 & 1.73 \\
\hline Psychological well-being & 60.24 & 10.4 & 56.57 & 9.1 & $2.0 *$ \\
\hline Psychological distress & 57.03 & 11.1 & 62.98 & 12.0 & $2.8 * *$ \\
\hline Mental Health Index & 171.36 & 19.2 & 161.72 & 17.9 & 1.0 \\
\hline
\end{tabular}

NOTE: SCD = sickle cell disease.

${ }^{*} p<.05 .{ }^{* *} p<.01$.

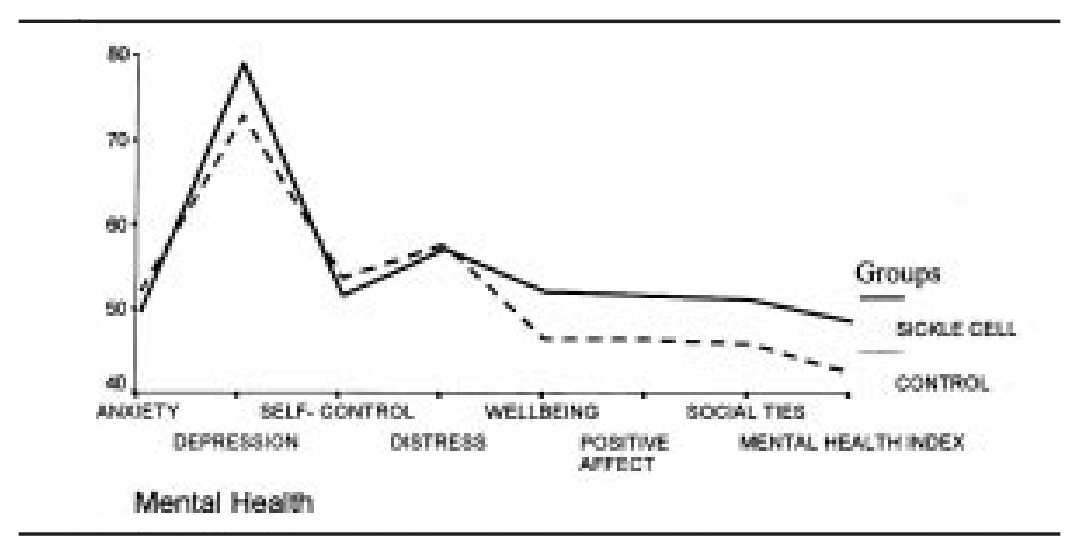

Figure 2: Standard Scores for Parents of Sickle Cell Disease and Control Children on Subscales of the Mental Health Inventory

These figures reveal that mothers and fathers of SCD children are lower on anxiety, loss of control, and distress than are parents of control children. Within each group, fathers reported lower levels of symptoms. This pattern is reversed when indicators of positive mental health are examined. Fathers of SCD children have the highest reported levels of overall mental health, positive effect, and psychological well-being followed by mothers of children 


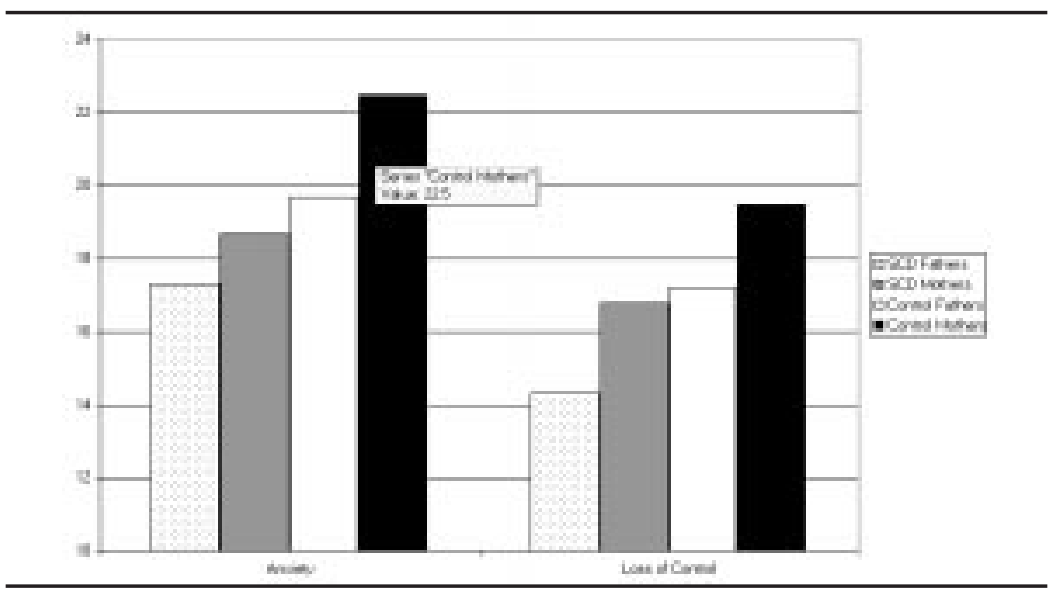

Figure 3: Parental Emotional Functioning NOTE: SCD = sickle cell disease.

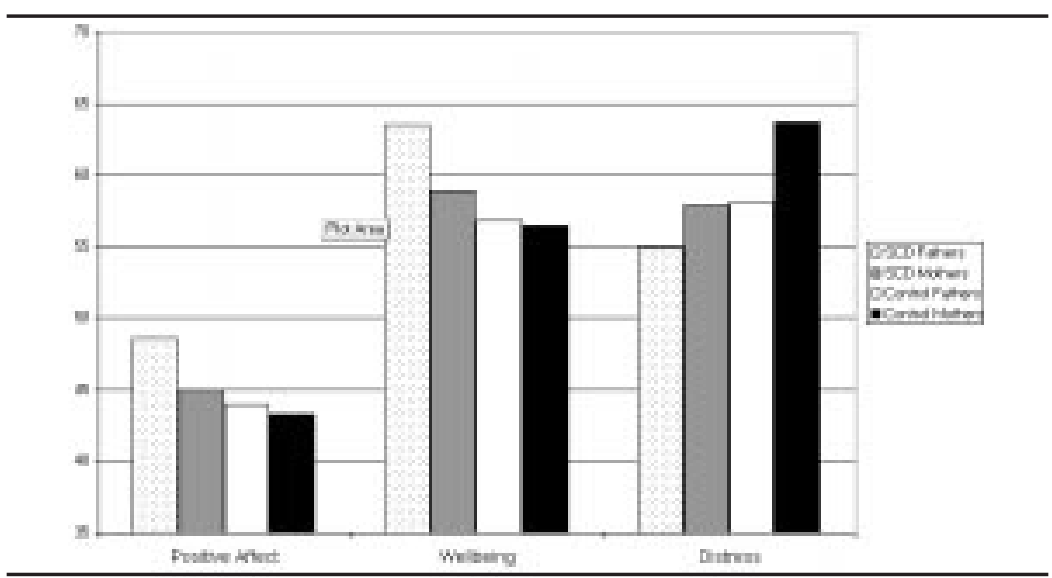

Figure 4: Stress and Well-Being Indicators for Parents of SCD and Control Children

NOTE: SCD = sickle cell disease.

with SCD, fathers of control children, and mothers of control children, respectively.

On measures of personal competence, no effect was observed among parents for health status. Table 4 presents the means and standard deviations for parents of SCD children and control children. The only significant $t$ value was found for social desirability. The means show that the parents of control children were higher in social desirability than the parents of SCD children. 


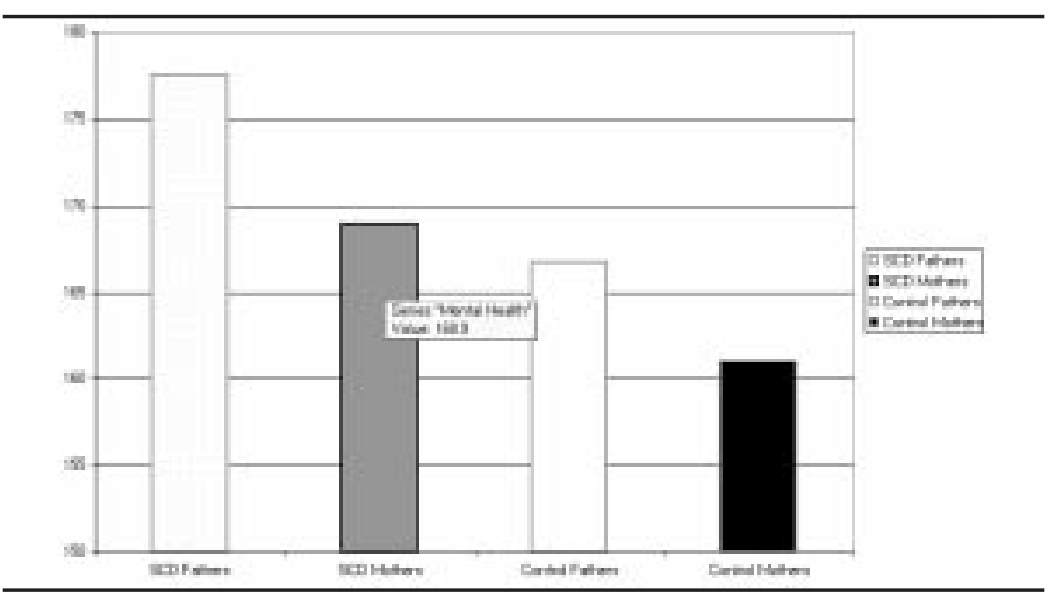

Figure 5: Total Mental Health Scores for Parents NOTE: SCD = sickle cell disease.

TABLE 4

Comparisons of Parents of SCD and Control Children on Measures of Personal Competence

\begin{tabular}{lrrrrrrr}
\hline \hline & \multicolumn{2}{c}{$S C D$} & & \multicolumn{2}{c}{ Control } & \\
\cline { 2 - 3 } & Mean & SD & & Mean & SD & t Value \\
\hline Personal mastery & 17.14 & 2.6 & & 16.55 & 2.2 & n.s. \\
Perceived helplessness & 9.30 & 2.9 & 9.06 & 3.9 & n.s. \\
Self-criticism & 7.27 & 2.8 & & 7.41 & 2.8 & n.s. \\
Positive evaluation & 17.79 & 2.7 & & 17.06 & 2.7 & n.s. \\
Life satisfaction & 8.16 & & 0.9 & & 8.14 & 0.9 & n.s. \\
Social desirability & 25.86 & 5.5 & & 28.83 & 4.0 & $3.23^{*}$ \\
\hline
\end{tabular}

NOTE: $\mathrm{SCD}=$ sickle cell disease; n.s. = not significant. $* p<.01$.

\section{FAMILY PROCESSES}

Results of the reports on family processes (organization and hierarchy) and on qualities of family relationships (support, conflict, differentiation, and emotional expressiveness) obtained from mothers and fathers of SCD and control children are presented in Table 5 in the form of raw scores. Families did not differ significantly on any of these dimensions. Figure 6 presents the data after they have been converted to standard scores based on a multiethnic standardization sample. The patterns for the two groups are similar 
TABLE 5

Comparisons of Parents of SCD and Control Children on the Family Process Scales

\begin{tabular}{lrrrrr}
\hline \hline & \multicolumn{2}{c}{$S C D$} & & \multicolumn{2}{c}{ Control } \\
\cline { 2 - 3 } & Mean & SD & & Mean & SD \\
\hline Differentiation & 23.82 & 2.7 & & 24.31 & 2.6 \\
Family support & 33.69 & 5.4 & & 33.88 & 4.2 \\
Family conflict & 9.91 & 2.7 & & 10.52 & 2.2 \\
Family organization & 14.07 & 3.5 & & 13.31 & 2.7 \\
Family hierarchy & 13.19 & 2.9 & & 13.35 & 2.3 \\
Emotional expressiveness & 16.28 & 2.9 & & 16.44 & 2.5 \\
Boundary maintenance & 27.11 & 4.0 & & 27.12 & 3.4 \\
\hline
\end{tabular}

NOTE: SCD = sickle cell disease.

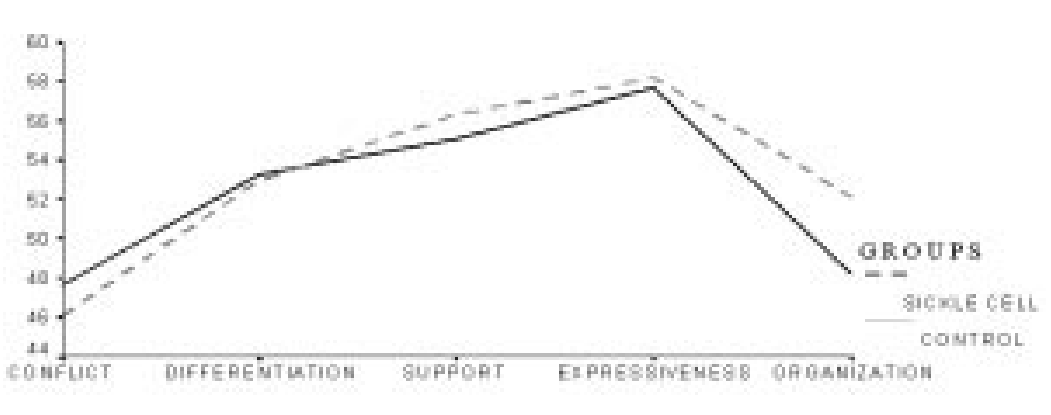

Figure 6: Standard Scores for Parents of Sickle Cell Disease and Control Children on the Family Process Scales

except that families of children with SCD are characterized as having higher levels of organization than are control families. In comparison to the standardization sample, the families in this study had average levels of differentiation and social support, relatively low levels of conflict, and moderately high levels of emotional expressiveness and organization.

\section{SOCIOCULTURAL VARIABLES}

Mean scores for parents of ill and healthy children for religiosity and racial identity did not differ significantly from one another, as shown in Table 6. When comparisons of mothers and fathers from the two groups are made on 
TABLE 6

Means and Standard Deviations for Parents of SCD and Control Children on Cultural Resources

\begin{tabular}{|c|c|c|c|c|c|}
\hline & \multicolumn{2}{|c|}{ Fathers } & \multicolumn{2}{|c|}{ Mothers } & \multirow[b]{2}{*}{ Total } \\
\hline & $\begin{array}{c}S C D \\
(\mathrm{n}=16)\end{array}$ & $\begin{array}{c}\text { Control } \\
(\mathrm{n}=6)\end{array}$ & $\begin{array}{c}S C D \\
(\mathrm{n}=55)\end{array}$ & $\begin{array}{l}\text { Control } \\
(\mathrm{n}=41)\end{array}$ & \\
\hline \multicolumn{6}{|l|}{ Religiosity } \\
\hline Mean & 6.8 & 6.2 & 6.8 & 6.5 & 6.6 \\
\hline Standard deviation & 3.0 & 1.0 & 2.0 & 2.0 & 2.0 \\
\hline \multicolumn{6}{|l|}{ Racial identity } \\
\hline Mean & 10.4 & 9.1 & 9.8 & 9.3 & 9.5 \\
\hline Standard deviation & 2.0 & 2.0 & 2.0 & 1.0 & 2.0 \\
\hline
\end{tabular}

NOTE: SCD = sickle cell disease.

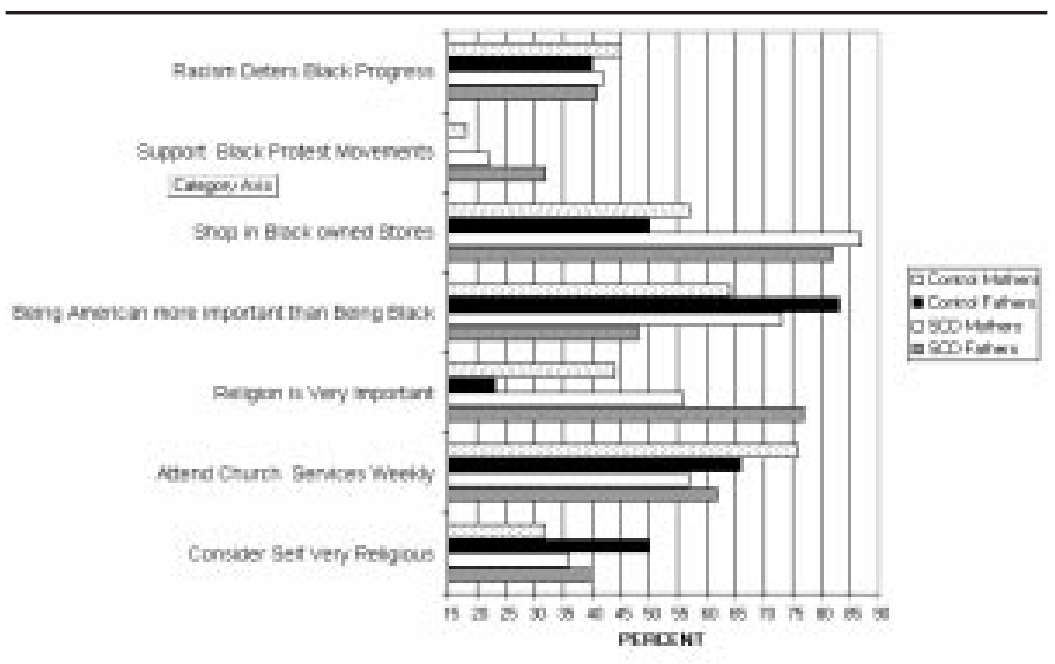

Figure 7: Religiosity and Racial Identity for Parents of SCD and Control Children NOTE: SCD = sickle cell disease.

responses to individual items, several important insights emerge. Figure 7 presents the percentages of mothers and fathers from the two groups who endorsed the different components of racial and religious ideologies. Approximately $40 \%$ of all groups felt that racism negatively affects Black progress. However, support from Black protest movements was most 
TABLE 7

Mean Ratings for Perceived Social Support by Health Status and Age Group

\begin{tabular}{|c|c|c|c|c|c|c|c|c|}
\hline & \multicolumn{4}{|c|}{$S C D$} & \multicolumn{4}{|c|}{ Control } \\
\hline & $4-7$ & $8-11$ & $12-15$ & $16-18$ & $4-7$ & $8-11$ & $12-15$ & $16-18$ \\
\hline & Years & Years & Years & Years & Years & Years & Years & Years \\
\hline All support sources & 5.7 & 5.3 & 4.8 & 3.8 & 3.0 & 4.7 & 1.6 & 5.5 \\
\hline Mothers & 8.1 & 10.0 & 8.9 & 9.6 & 6.0 & 7.5 & 6.6 & 8.6 \\
\hline Fathers & 6.9 & 8.6 & 7.2 & 7.3 & 4.5 & 6.2 & 5.3 & 6.3 \\
\hline Siblings & 6.7 & 8.5 & 6.9 & 7.7 & 4.4 & 6.1 & 5.7 & 8.2 \\
\hline Friends & 4.6 & 5.4 & 4.1 & 5.0 & 2.0 & 3.1 & 2.9 & 5.0 \\
\hline
\end{tabular}

NOTE: SCD = sickle cell disease.

strongly endorsed by fathers of SCD children. More than half of all groups reported attending weekly church services. In general, parents of SCD children reported being more religious and asserting Black identity more strongly than did parents of control children. Interestingly, fathers in this sample considered themselves very religious, with close to $50 \%$ of the fathers of control children endorsing this item.

\section{SOURCES OF SOCIAL SUPPORT FOR CHILDREN}

The supportive quality of relationships with mothers, fathers, siblings, and friends was rated by ill children and the non-ill comparison group. In addition, children reported on the extensiveness of their support networks by indicating whether they had received support from a list of probable support sources. Table 7 presents the mean ratings of support disaggregated by age and health status. Multivariate and univariate $F$ values were computed to test the statistical effects of age and health status and their interaction. The multivariate effect for age was significant, $F(3,74)=1.8, p<.023$. Hotelling's multiple $F$ for health status also was significant, $F(1,75)=8.81, p<.001$. The univariate $F$ values were significant for all sources of support: mothers, $F(1$, $75)=20.17, p<.001$; fathers, $F(1,75)=11.44, p=.001$; siblings, $F(1,75)=$ $5.96, p<.05$; and friends, $F(1,75)=21.68, p<.001$. The effects for age were significant for mothers, $F(3,74)=4.34, p<.01$; siblings, $F(3,74)=3.65, p<$ .01 ; and friends, $F(3,74)=5.15, p<.01$. The interaction was significant only for friends, $F(3,74)=2.78, p<.05$. The results show that across all support sources, ill children reported higher levels of support than did control 
children. Mothers received the highest support ratings. The highest rating for fathers came from ill children 8 to 11 years of age, and the lowest came from healthy children 4 to 7 years of age. However, there were no significant age effects on children's ratings of support from fathers. Siblings' highest support ratings were made by ill children 8 to 11 years of age and healthy control children 16 to 18 years of age. Sibling support was rated most highly by children 8 to 11 years of age. There was a significant interaction of age group and health status on support from friends. Ill children under 8 years of age received a significantly higher quality of support from friends compared to their non-ill counterparts.

\section{ATTRIBUTIONS ABOUT THE CAUSE OF SCD}

One aspect of coping assessed in this study is the meaning that children attached to illness and the attributions made about its causes and controllability. Table 8 presents reports of the frequencies with which children and adolescents think about the causes of their illness, the specific causes to which they attribute the disease, and the chi-square analysis of the differences between the young children and the adolescents. The data show a number of differences in attributional processes used in making sense of their illness experience. In general, these differences are consistent with extant notions about developmental differences in reasoning abilities. For example, an overwhelming majority of adolescents reported questioning why the illness occurs, but fewer than half of the young children did. More adolescents than young children have developed some paradigm for explaining the illness. Table 8 presents specific reasons for the disease in the order of the most frequently mentioned to the least frequently mentioned. The most common explanation, "just born with it," probably reflects the success of disease education and counseling programs with parents and children that emphasize genetic explanations and the fact that the disease is congenital. Many more young children than adolescents believe that they can stop it, although this belief more likely refers to symptoms of SCD than to its fundamental pathogenesis.

Interestingly, adolescents, unlike most young children, integrated religious interpretations into their paradigms about the etiology of the disease. This is interesting and important because it suggests how religious ideology might be implicit in adolescents' efforts to cope with the disease. The belief that it was God's will that these persons have the disease provides the basis for resignation and acceptance that might support efforts to regulate their emotional reaction to pain and life disruption caused by the disease. These 
TABLE 8

Age Differences/Causal Attributions About Illness Among Children With Sickle Cell Disease

\begin{tabular}{lccc}
\hline \hline & Children & Adolescents & $\chi^{2}$ \\
\hline Attributions/thinking & & & \\
$\quad$ Ever wonder why & 41 & 70 & n.s. \\
$\quad$ Have any idea why & 25 & 38 & n.s. \\
Specific attributions & & & \\
$\quad$ Just born with it & 55 & 67 & n.s. \\
Possible for child to stop it & 52 & 56 & $7.4^{*}$ \\
God willed it & 26 & 13 & $15.0^{* *}$ \\
Accidental cause & 30 & 22 & $6.0^{* *}$ \\
Caused by bad luck & 13 & 15 & n.s. \\
Environmental cause & 15 & 0 & $6.2^{*}$ \\
$\quad$ Own fault & 8 & & \\
\hline
\end{tabular}

NOTE: n.s. $=$ not significant $* p<.05 . * * p<.01$.

aversive conditions are imbued with a transcendental meaning that facilitates coping. For some other adolescents (22\%), the world might not be as orderly or God as providential; the disease was attributed to bad luck. Nearly a third of children attributed the disease to some accident. Other responses suggested that young children see the illness as more controllable than it is in reality and, consequently, might blame themselves or their parents more often than might older children. None of the adolescents blamed himself or herself for the illness, whereas $7.5 \%$ of the young children did. Young children as a group felt that they could have done something to prevent the illness more often than did adolescents ( $52 \%$ vs. $36 \%$ ) and, at the same time, attributed the illness to accidental causes more often than did adolescents (30\% vs. $13 \%$ ). Given that SCD has a $25 \%$ chance of occurring in conjugal unions between men and women with the sickle cell trait, this explanation might not be far off the mark.

\section{MAKING DECISIONS ABOUT CHILDREN'S LIVES}

Children and parents responded independently to inquiries about who was most influential in making mundane decisions about the children's lives. Table 9 presents the means, standard deviations, and $t$ values testing the significance of differences between parents of SCD children and those of control children in decision making. Parents of SCD children were significantly 
TABLE 9

Means and Standard Deviations for Parents' Reports of Decision Making and Involvement in Children's Lives by Health Status

\begin{tabular}{lcccccc}
\hline \hline & \multicolumn{2}{c}{$S C D$} & & \multicolumn{2}{c}{ Control } & \\
\cline { 2 - 3 } & Mean & SD & & Mean & SD & t Value \\
\hline Child autonomy & 10.24 & 5.6 & & 13.48 & 5.7 & $3.42^{* * * *}$ \\
Collaboration & 4.39 & 3.8 & & 3.83 & 3.0 & n.s. \\
Parental control & 4.09 & 2.9 & & 2.88 & 3.0 & $2.1^{*}$ \\
Parental academic involvement & 5.41 & 2.6 & & 5.86 & 2.7 & n.s. \\
\hline
\end{tabular}

NOTE: SCD = sickle cell disease; n.s. = not significant. $* p<.05 . * * * p<.001$.

lower in granting children decision-making autonomy and higher in decision-making control than were parents of control children.

Children's responses to who controls decision making generally corroborated parental responses. Table 10 presents the percentages of SCD and control children who reported having decision-making autonomy over several areas of their lives. Because the degree of autonomy granted by parents and assumed by children is influenced by developmental stage, these data are disaggregated by age group to permit within-age group comparisons of SCD and control children. Striking differences are observed among children under 6 years of age. In contrast to similarly aged control children, none of the SCD children reported autonomy in any of the domains tested. Parents of young SCD children tended to be more controlling or protective than did parents of young control children. Parents of control children tended to extend more autonomy to children under 9 years of age than did parents of SCD children. The lack of involvement at 4 and 5 years of age was reported by children 6 to 8 years of age with respect to selecting friends and how money is spent.

From approximately 9 or 10 years of age, children assume control over what they eat and the friends they make. Predictably, by the time they were in their late teens, the SCD and control groups reported assuming control over decision making in most areas. An exception to the absolute autonomy by adolescence relates to deciding about whether one is too sick to attend school. Only one out of five SCD respondents and two out of five control respondents reported having autonomy in making this decision. SCD children seemed to lag 2 to 3 years behind control children in attaining autonomy. For example, the majority of control children reported autonomy with respect to friends by 9 to 11 years of age, whereas this did not happen until 12 to 13 years of age for 
TABLE 10

Percentages of Children Who Reported Autonomy in Making Mundane Decisions by Age Group and Health Status

\begin{tabular}{|c|c|c|c|c|c|c|c|c|c|c|}
\hline & \multicolumn{2}{|c|}{ 4-5 Years } & \multicolumn{2}{|c|}{ 6-8 Years } & \multicolumn{2}{|c|}{ 9-11 Years } & \multicolumn{2}{|c|}{ 12-13 Years } & \multicolumn{2}{|c|}{ 14-16 Years } \\
\hline & $S C D$ & Control & $S C D$ & Control & $S C D$ & Control & $S C D$ & Control & $S C D$ & Control \\
\hline What you eat & 0 & 20 & 11 & 47 & 80 & 35 & 67 & 40 & 71 & 90 \\
\hline Friends you may play with & 0 & 27 & 0 & 50 & 50 & 74 & 67 & 50 & 86 & 90 \\
\hline How much time spent with friends & 0 & 27 & 22 & 0 & 30 & 57 & 78 & 80 & 79 & 90 \\
\hline Activities/games you may play & 0 & 45 & 22 & 60 & 60 & 61 & 56 & 53 & 86 & 60 \\
\hline How much television you watch & 0 & 27 & 11 & 20 & 30 & 48 & 33 & 30 & 64 & 70 \\
\hline How you spend money & 0 & 36 & 0 & 53 & 80 & 61 & 56 & 80 & 64 & 80 \\
\hline Type of clothing you wear & 0 & 18 & 11 & 20 & 30 & 13 & 33 & 50 & 36 & 50 \\
\hline Type of hairstyle you wear & 0 & 9 & 33 & 31 & 30 & 26 & 78 & 60 & 57 & 60 \\
\hline Amount of time on homework & 0 & 9 & 22 & 20 & 60 & 52 & 56 & 30 & 71 & 50 \\
\hline If you are too sick to attend school & 0 & 18 & 11 & 6 & 10 & 9 & 22 & 0 & 21 & 40 \\
\hline
\end{tabular}

NOTE: $\mathrm{SCD}=$ sickle cell disease. 
TABLE 11

Percentages of Parents Indicating Academic Involvement With SCD and Control Children

\begin{tabular}{lccc}
\hline \hline & $S C D$ & Control & $\chi^{2}$ \\
\hline Contact child's teacher & 91 & 89 & $4.0^{*}$ \\
Attend school activities & 70 & 85 & 81 \\
Read to child & 77 & 87 & 87 \\
Review homework & 92 & 74 & $3.6^{*}$ \\
Attend parent-teacher conferences & 82 & 53 & \\
Visit classroom & 67 & 89 & \\
Secure tutor for child & 69 & & \\
Teach child life skills & 90 & & \\
\hline
\end{tabular}

NOTE: SCD = sickle cell disease.

$* p<.05$.

SCD children. Similarly, a majority of the control group children reported autonomy over activities by 6 to 8 years of age, whereas this did not happen until 9 to 11 years of age for the SCD group.

\section{ACADEMIC INVOLVEMENT BY PARENTS}

A major exception to a higher level of parental involvement in decision making among parents of SCD children is in regard to deciding how much time is spent on homework. Between 9 and 11 years of age, most SCD children make this decision. This could be a case in which autonomy might not be beneficial. The academic problems often reported among children with SCD might go unchecked in the absence of sufficient monitoring and involvement by parents. However, a very high percentage of parents described themselves as very involved in the academic lives and homework of their children. For example, $87 \%$ of the non-ill children and $92 \%$ of the ill children said that parents reviewed their homework. More than half of the parents described themselves as being involved with their children's teachers, attending school activities, reading to their children, reviewing homework, visiting classrooms, and getting tutors for their children when needed. The major differences between the ill children and non-ill children were that parents of non-ill children were much more likely to report attending school activities than were parents of ill children and that parents of non-ill children were less likely to seek out tutoring for their children (Table 11). This finding might be a result of the availability of services to ill children. In fact, children in this 
TABLE 12

Comparisons of Self-Reported and Parent-Reported Mental Health Indexes for SCD and Control Children

\begin{tabular}{|c|c|c|c|c|c|}
\hline & \multicolumn{2}{|c|}{$\begin{array}{c}S C D \\
(\mathrm{n}=73)\end{array}$} & \multicolumn{2}{|c|}{$\begin{array}{l}\text { Control } \\
(\mathrm{n}=92)\end{array}$} & \multirow[b]{2}{*}{$\mathrm{t}$ Value } \\
\hline & Mean & SD & Mean & $\mathrm{SD}$ & \\
\hline \multicolumn{6}{|l|}{ Reports by child } \\
\hline $\begin{array}{l}\text { Children's Depression Inventory- } \\
\text { depression }\end{array}$ & 11.26 & 7.7 & 17.26 & 16.5 & $2.32 *$ \\
\hline $\begin{array}{l}\text { Children's Manifest Anxiety- } \\
\text { anxiety }\end{array}$ & 12.24 & 7.0 & 10.92 & 6.1 & \\
\hline \multicolumn{6}{|l|}{ Child Behavior Checklist } \\
\hline Total problems & 56.14 & 12.4 & 58.42 & 10.2 & \\
\hline Externalizing problems & 13.35 & 10.4 & 20.10 & 15.3 & $2.80 * *$ \\
\hline Internalizing problems & 14.07 & 12.5 & 13.24 & 11.5 & \\
\hline Social competence & 15.11 & 3.3 & 17.04 & 3.7 & $2.59 * *$ \\
\hline \multicolumn{6}{|l|}{ Behavior Problem Index } \\
\hline Antisocial behavior & 1.33 & 2.0 & 2.21 & 1.9 & $2.34 * *$ \\
\hline Opposition & 1.39 & 1.4 & 2.88 & 3.4 & $2.31 * *$ \\
\hline Social problems & 5.58 & 1.7 & 6.38 & 2.3 & $2.15^{* *}$ \\
\hline
\end{tabular}

NOTE: $\mathrm{SCD}=$ sickle cell disease.

$* p<.05 . * * p<.01$.

study had a program that provided tutors. So, this difference might be explained more by the readiness to access available services than by a disposition to secure resources the children might need to enhance their academic achievement. For this reason, we cannot conclude that parents of ill children are more conscious of, supportive of, or attentive to the academic needs of their children, nor should we conclude that they are more ready and able to secure resources children need when they face academic difficulties.

\section{CHILD DEVELOPMENTAL OUTCOMES}

Contrary to expectations, children with SCD are significantly lower than control children on most of the indexes of psychological problems examined in this study including CDI-depression, CBCL externalizing problems and antisocial behavior, and opposition and social problems on the BPI. They also were significantly lower in social competence. No significant differences were found on the CMA anxiety or the total problems and internalizing conditions as measured by the CBCL (Table 12). Figure 8 depicts the 


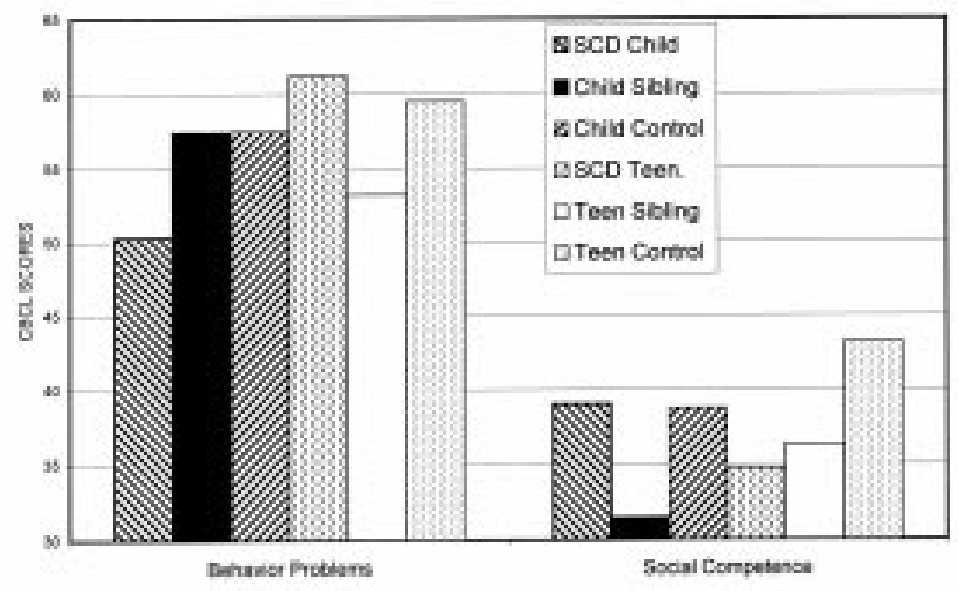

Figure 8: Problem and Competence Scores for SCD Children, Siblings, and Control Children

NOTE: $\mathrm{SCD}=$ sickle cell disease; $\mathrm{CBCL}=$ Child Behavior Checklist.

standardized scores for the CBCL total behavior problems on one line and the total social competence on the other line. The points on each line represent the scores for the respondents disaggregated by health status (children with SCD vs. their siblings vs. controls) and by age (young children vs. adolescents or teens). For total behavior problems, all groups fall below the clinical range except the SCD teens. On this subscale, the young children with SCD were the closest to the average score of 50. It is almost as though SCD has a suppressive effect on behavior problems for children based on their low scores relative to those of their siblings and healthy peers. The case is very different for adolescents. In this case, the SCD might be a risk factor for problems, with their scores being much higher than those of siblings and slightly higher than those of healthy peers. Tests of the significance of these differences were made using a three-way analysis of variance. Main effects for health status, age group, and gender were not significant. However, the interaction between age group and health status was significant, $F(2,145)=3.67$, $p<.02$. With respect to social competence, most of the children scored below average. Teen controls did the best of all the groups on this dimension and fell within in the normal range (45-50). Young siblings showed the largest social deficits, but the teens with SCD also showed evidence of significant decrements in social competence. The analysis of variance for social competence yielded results similar to those reported for behavior problems, namely, no 


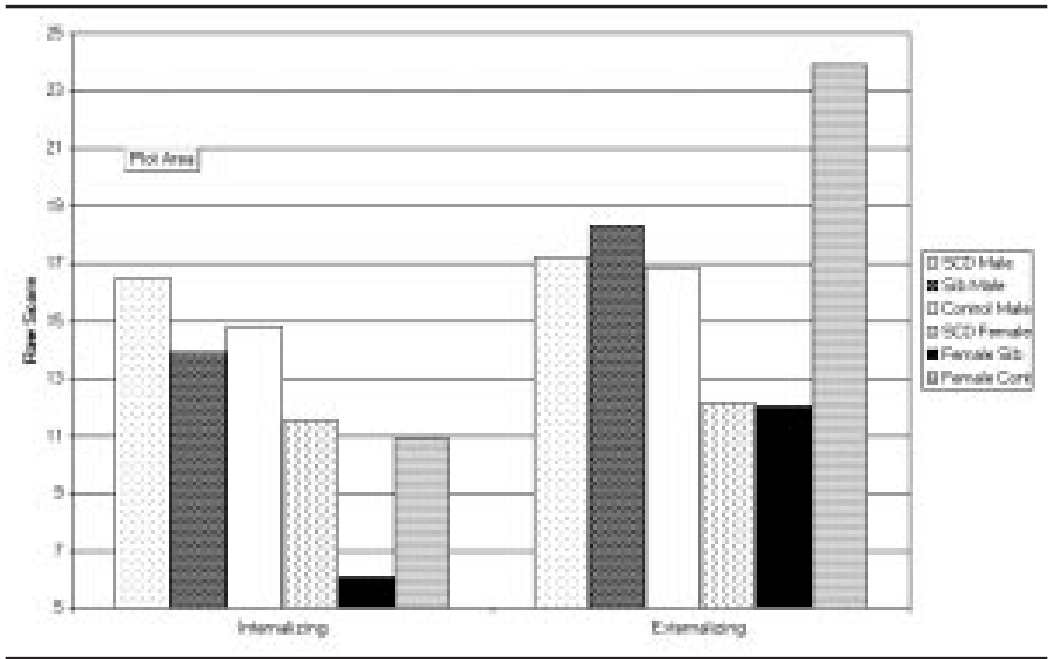

Figure 9: Behavior and Emotional Problems by Gender and IIIness Status NOTE: $\mathrm{SCD}=$ sickle cell disease; $\mathrm{Sib}=$ sibling; Cont $=$ control.

significant main effects but a significant interaction between age group and health status, $F(2,145)=4.45, p<.01$.

Figure 9 depicts the raw scores for the CBCL internalizing and externalizing scales broken down by gender and age groups. For internalizing symptoms, SCD males have the highest scores and female siblings have the lowest scores. However, males with SCD do not differ very much from male siblings and healthy controls. Females with SCD do not differ very much on the internalizing scale but are much lower on externalizing symptoms than are female controls.

Figure 10 presents the mean raw scores for the same groups on the three subscales that make up the total social competence score for the CBCL. Males with SCD are slightly lower than male controls on the social subscale. The scores of male and female siblings are low relative to those of their healthy counterparts.

Figure 11 presents the standard scores by the age and health status groups for depression, anxiety, behavior problems, social competence, and social desirability for males. Figure 12 presents similar data for females. Social desirability scores are low for all groups and is highest among young females. Among the males, depression scores fall below the clinical level for all groups except child siblings. Anxiety scores are low or about the same for all groups except child siblings. Among girls, the social competence scores are 


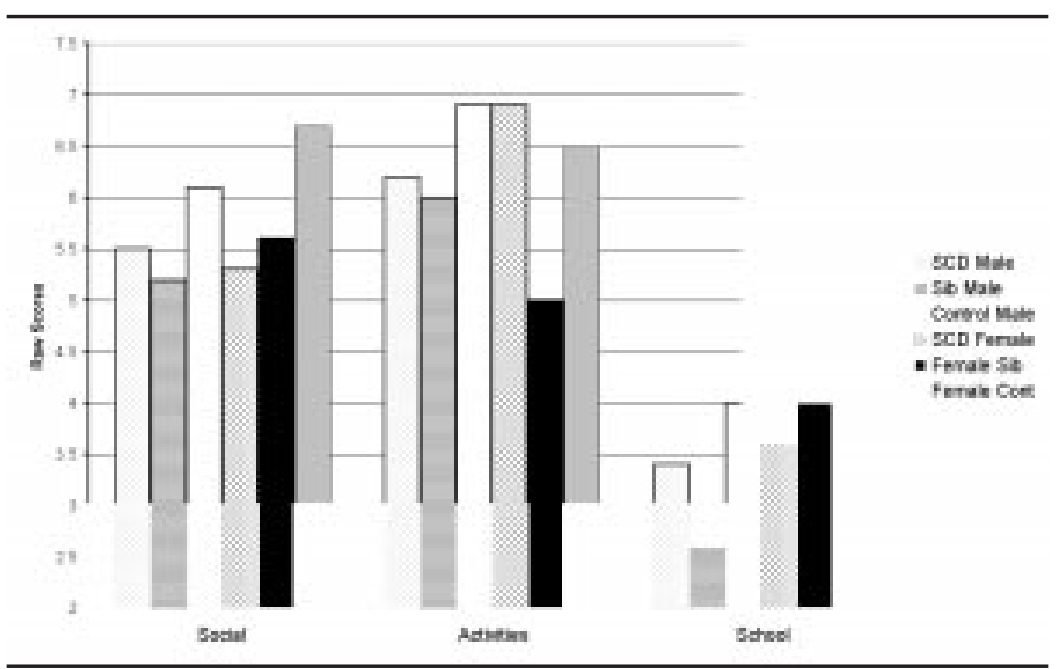

Figure 10: Social Competence by Gender and Health Status

NOTE: SCD = sickle cell disease; Sib = sibling; Cont = control.

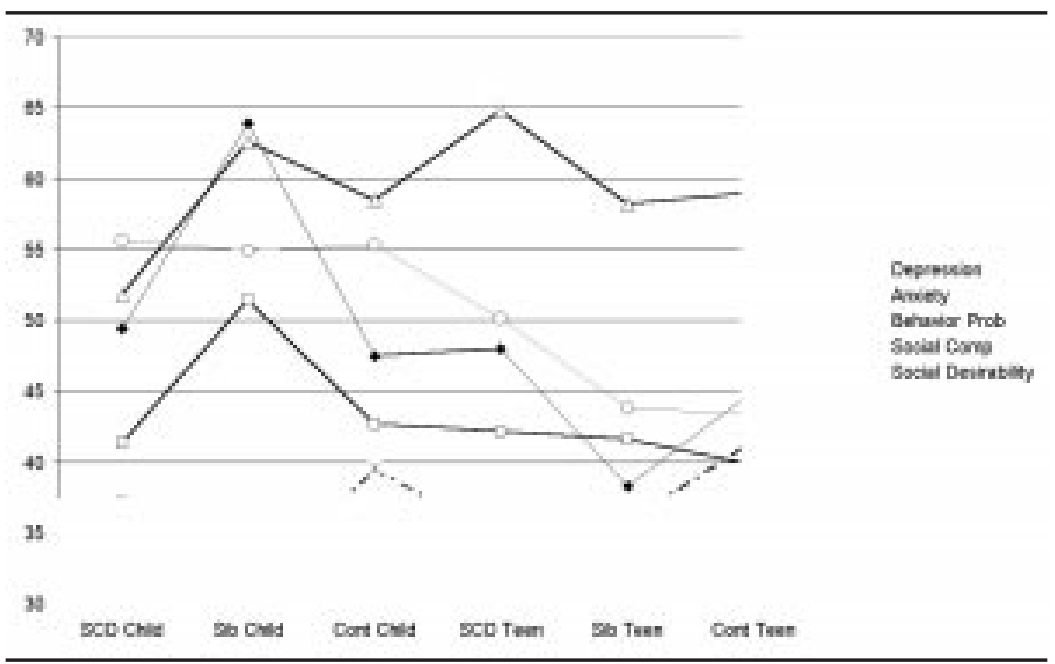

Figure 11: Mental Health for Boys by Age Group and IIIness Status

NOTE: SCD = sickle cell disease; $\mathrm{Sib}=$ sibling; Cont = control; Prob = problems; Comp = competence.

low, particularly those of teens with SCD. Unlike the male child siblings, females have low anxiety scores. However, the female teen controls have elevated depression scores that go along with elevations in behavior problems. 


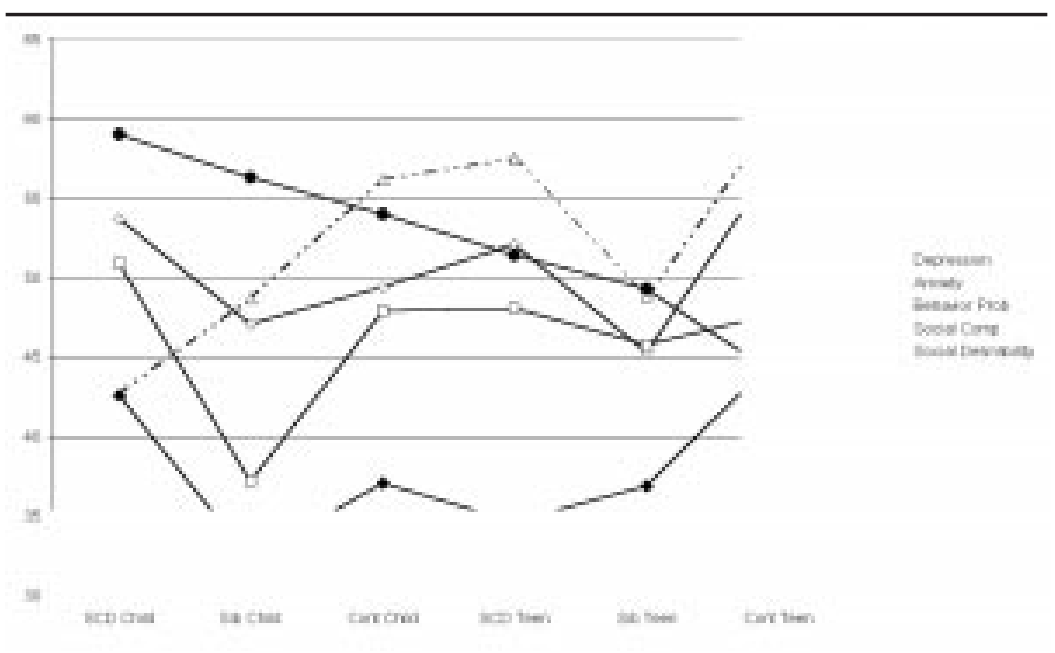

Figure 12: Mental Health for Girls by Age Group and IIIness Status

NOTE: $\mathrm{SCD}=$ sickle cell disease; $\mathrm{Sib}=$ sibling; Cont = control; Prob = problems; $\mathrm{Comp}=$ competence.

\section{MODEL PREDICTING TOTAL BEHAVIOR PROBLEMS}

A series of multiple regressions were computed to test the model presented in Figure 1. The analysis proceeded by testing the group of variables for each domain (stress, family life, and coping) one at a time. For each domain, an attempt was made to identify the variables that were significantly related to the CBCL total behavior problem scores and the total social competence scores. The variables identified in this way were retained and used in the final test of the model. They included the degree of medical stress, support from mothers and fathers, religiosity of the parents, degree of conflict in family life, social ties of parents, level of parental distress, and extent to which racial attributions are used to explain the conditions or outcomes of African Americans in this country. Whereas all of these variables were significantly related for predicting the outcome, the most powerful combination of variables for predicting the total problems scored on the CBCL is the psychological distress of the parents, the social ties of and support received by the parents, the stress or life changes produced by the illness, and the extent to which racial attributions are used to explain the condition of Blacks in this country (Figure 13).

The degree of medical stress, support from the mother and father, parental religiosity, and degree of conflict, although important in the early steps of the 


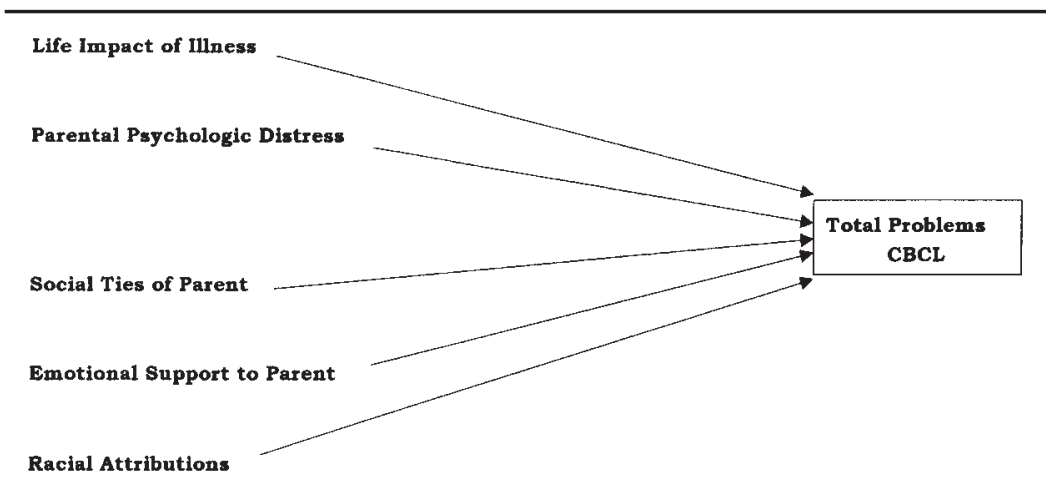

Figure 13: Model Parameters Predictive of Suboptimal Psychological Outcomes for Children With Sickle Cell Disease

NOTE: $\mathrm{CBCL}=$ Child Behavior Checklist.

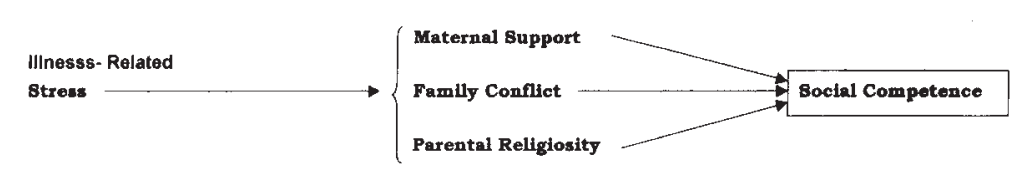

Figure 14: Model of Family Mediation of Social Competence in Children With Sickle Cell Disease

models, were not significant in the final model. The sociocultural and parental functioning domains of the model received the strongest support as predictors of a combination of internalizing and externalizing disorders captured in the total problem behavior subscale from the CBCL. These include family support for and social ties of the parents, parental distress, life impact of the illness reported by the children, and racial attributions.

Psychological disorders were less likely to occur in children when parents received a high level of support from their families and were less psychologically distressed themselves, when they used racial attributions to explain the failures of Black people, and when children experienced less impact of the illness on their lives. In a second model, children were more likely to be high in social competence when the illness had less of an impact on their lives, when parents were more supportive, and when parents were more religiously oriented. Presumably, maternal support of the ill children, low levels of family conflict, and high levels of parental religiosity moderated the adverse impacts of illness on social competence (Figure 14). 


\section{SUMMARY OF FINDINGS}

Illness-related stress in SCD. Ill children more frequently reported fatigue and disturbances of sleep than did healthy children. In addition, ill adolescents reported problems with bed-wetting and low body weight significantly more often than did their healthy counterparts. Mood disturbances and the desire to be left alone, which often have been cited as sequelae of serious illness, were cited more frequently by healthy adolescents than by ill adolescents.

Adverse life impact of illness. The most frequently reported adverse impact of the illness was on grades in school and on recreational or social activities. The impact of the severity of the illness was related to emotional adjustment.

Meaning of SCD. The meaning and significance attached to SCD by the children depended on age. Most children viewed SCD as a random, unexplainable event over which they had little control. However, young children (under 12 years of age) thought of the illness as preventable and blamed themselves more often than did adolescents. Children who reached adolescence had available to them many abstractions that they could use to make sense of their illness. For example, adolescents attributed SCD to God's will or to bad luck more often than did younger children.

Social and emotional support. Children with SCD rated the quality of supportive relationships with mothers, fathers, siblings, and friends significantly higher than did healthy controls. However, control adolescents reported support networks that were more extensive than those of adolescents with SCD.

Personal autonomy of children with SCD. Parents of children with SCD were more frequently and more deeply involved in decision making about the mundane aspects of their children's lives than were parents of healthy children. Although they were more involved in children's use of time and choices about activities, these parents were less involved in their children's school lives than were parents of healthy control children.

Main effects of SCD on psychological functioning. Illness did not have the predicted relationship to children's self-reports of anxiety or depressive symptoms. However, illness did adversely affect development of social competence in adolescents. 
Functional disruptions of and the impact on socioemotional adjustment. The key factor in understanding the adverse effects of the illness on psychological functioning is disruption of life consequent to the illness, not the diagnosis or symptom severity per se. Ill children whose lives were more severely changed by the illness had more serious psychological difficulties than did children who tried to go on with as normal lives as possible. Even though children with chronic illness as a group were not significantly different from healthy children on emotional or behavioral problems, psychological wellbeing of ill children was dependent on how much the illness disrupted their lives in terms of social relations, school life, and age-appropriate recreational activities.

Illness as a protective factor. Surprisingly, SCD appeared to protect young African American males against the risk of conduct problems. Young males with SCD had lower levels of conduct problems than did their healthy counterparts.

Socioemotional functioning of siblings. With respect to the development of psychological difficulties, the illness by itself was unexpectedly less of a risk factor than was being the sibling of a seriously ill child. Siblings were higher on self-reported scores of depression and parent-reported scores of behavior problems than were ill children and children in the healthy comparison group. (This effect occurred primarily in young males.) The impact on psychological functioning of being a sibling also depended on gender. Being the sibling of an ill child was a risk factor for males but a protective factor for females.

Age and gender effects on depression. Age and gender were related to psychological functioning in the expected manner. Younger males had higher levels of self-reported depression than did older males. Similar trends have been noted in large national samples of African American children (Barbarin \& Soler, 1993).

Family functioning, sociocultural factors, and psychological outcomes. Development of social competence was associated with children's perceptions of maternal support, low levels of family conflict, and high parental religiosity. Psychological problems (internalizing and externalizing disorders) were less likely to occur when parents received high levels of support from their own families and had strong emotional ties to friends and kin, when parents had low levels of psychological distress, when the illness led to 
fewer life changes for the ill children, and when parents drew on racial attributions in explaining life outcomes of African Americans.

\section{DISCUSSION}

Social functioning could be one of the most serious areas of dysfunction among children and adolescents with SCD. However, this might stem as much from being poor and Black as having SCD. The entire sample fell more than 1 full standard deviation below the mean with respect to social competence. The group with the lowest scores was adolescent male ill children and their healthy siblings. Thus, the illness seems to have an effect on social functions. This is understandable given that measures of social competence include not only friends and academic performance but also the degree to which one remains active in developing a set of interests and activities. The dearth of engaging activities and organized recreation for young children in African American communities is a focus of much discussion but little action. The results on the CBCL say as much about inadequate community resources as about social ineffectiveness. In addition, the pressing and constant demands of caring for ill children while working might leave little time for families to connect healthy siblings with enrichment activities and events outside of the home. Thus, siblings might be most adversely affected by illness.

\section{IMPLICATIONS OF THIS RESEARCH}

Although illness did not have a consistently adverse effect on psychological function, African American children showed a high risk of behavioral and emotional difficulties. Moreover, this research identified several distinct groups that might be at risk for psychological difficulties and several protective factors within the family that might be the target of preventive intervention. The subgroups of children who appeared to be at greatest risk of poor psychological development were young male siblings of ill children, ill adolescents, children whose lives were most severely disrupted by illness, and healthy adolescents.

The value and effectiveness of social support for parents is unquestionable. Moreover, religiosity, a personal relationship with God, and social connection to a community of worship were important resources in coping with the demands of illness and in fostering healthy psychological development of children. Children of parents who were successful, either on their own or with 
help, in managing psychological distress had fewer difficulties. With respect to psychological functioning, ill children did not constitute a distinct class. Non-ill children were just as likely to experience problems of emotional and behavioral adjustment. However, among ill children, preventive interventions should be targeted to those who experience functional impairment related to school and peer interactions.

What was most surprising was the limited direct effect of chronic illness on the psychological functioning of ill children and the apparently large effect on siblings. Being diagnosed with a serious illness was not enough to make a difference in terms of psychological adjustment. However, psychological well-being of ill children was directly related to the extent to which serious illness led to or caused deviations from what most children consider to be a normal life with respect to peer contacts, participation in ageappropriate recreational activities, interpersonal relations with families and friends, and how one is treated by others. There, the risk of psychological dysfunction associated with illness is less directly dependent on disease symptoms or illness severity as indexed by physical condition than on how they affect children's functionality. The primary adverse impact of the illness is in the domain of social competence. This is particularly true for ill adolescents. The lack of significant differences between chronically ill children as a total group and children in the healthy comparison group is only half of the story told by the data from this study. The other half is that, on average, the mean scores on the combination internalizing and externalizing disorders for the entire sample hovered close to the clinical range. African American children from poor communities were viewed by their parents as having significant difficulties, and serious illness was not the most important factor differentiating them with respect to emotional development.

\section{REFERENCES}

Achenbach, T. М. (1991). Manual for the Child Behavior Checklist/4-18 and 1991 profiles. Burlington: University of Vermont, Department of Psychiatry.

Barbarin, O. (1983). Coping with ecological transitions by Black families: A psychosocial model. Journal of Community Psychology, 11, 308-322.

Barbarin, O. (1990). Adjustment to serious childhood illness. In B. Lahey \& A. S. Kazdin (Eds.), Advances in clinical child psychology (Vol. 13, pp. 377-403). New York: Plenum.

Barbarin, O. (1996). The Family Relations Scale: Manual. Ann Arbor, MI: Assessment Psychometrika.

Barbarin, O., Sargent, J., Sahler, O. J., Roghmann, K., Mulhern, R., Carpenter, P., Copeland, D., Dolgin, M., \& Zeltzer, L. (1995). Sibling adaptation to childhood cancer: Collaborative 
research project-Parental views of pre- and post-diagnosis functioning of siblings of children with cancer. Journal of Psychosocial Oncology, 13, 1-20.

Barbarin, O., \& Soler, R. (1993). Behavioral, emotional, and academic adjustment in a national probability sample of African American children: Effects of age, gender, and family structure. Journal of Black Psychology, 19, 423-446.

Fredrick D. Patterson Research Institute. (1997). The African American education data book (Vol. 2). Alexandria, VA: United Negro College Fund.

Jackson, J., Gurin, P., Hatcher, S., \& Bowen, P. (1979). National Survey of Black Americans. Ann Arbor, MI: Institute for Social Research.

Kliewer, W., \& Lewis, H. (1995). Family influences on coping processes in children and adolescents with sickle cell disease. Journal of Pediatric Psychology, 20, 511-525.

Kovacs, M. (1985). The Children's Depression Inventory (CDI). Psychopharmacology Bulletin, 21, 995-998

Lewis, H. A., \& Kliewer, W. (1996). Hope, coping, and adjustment among children with sickle cell disease: Tests of mediator and moderator models. Journal of Pediatric Psychology, 21(1), 25-41.

McLoyd, V. C. (1998). Socioeconomic disadvantage and child development. American Psychologist, 53, 185-204.

Menaghan, E. G. (1983). Individual coping efforts and family studies: Conceptual and methodological issues. Marriage and Family Review, 6, 113-135.

Noll, R. B., Vannatta, K., Koontz, K., Kalinyak, K., Bukowski, W. M., \& Davies, W. H. (1996). Peer relationships and emotional well-being of youngsters with sickle cell disease. Child Development, 67, 423-436.

Pearlin, L., \& Schooler, C. (1978). The structure of coping. Journal of Health and Social Behavior, 19, 2-21.

Peterson, J., \& Zill, N. (1986). Marital disruption, parent-child relationships, and behavior problems in children. Journal of Marriage and the Family, 48, 295-307.

Reynolds, C. R., \& Richmond, B. O. (1978). What I think and feel: A revised measure of children's manifest anxiety. Journal of Abnormal Psychology, 6, 271-280.

Richard, H. W., \& Burlew, A. K. (1997). Academic performance among children with sickle cell disease: Setting minimum standards for comparison groups. Psychological Reports, 81(1), 27-34.

Sterling, Y. M., Peterson, J., \& Weekes, D. P. (1997). African American families with chronically ill children: Oversights and insights. Journal of Pediatric Nursing, 12, 292-300.

Veit, C. T., \& Ware, J. E., Jr. (1983). The structure of psychological distress and well-being in general populations. Journal of Consulting and Clinical Psychology, 51, 730-742.

Wasserman, A. L., Wilimas, J. A., Fairclough, D. L., Mulhern, R. K., \& Wang, W. (1991). Subtle neuropsychological deficits in children with sickle cell disease. American Journal of Pediatric Hematology-Oncology, 13(1), 14-20.

Whitten, C., \& Nishiura, E. (1985). Sickle cell anemia: Public policy issues. In N. Hobbs \& J. Perrin (Eds.), Issues in the care of children with chronic illness (pp. 236-260). San Francisco: Jossey-Bass.

Yang, Y. M., Cepeda, M., Price, C., Shah, A., \& Mankad, V. (1994). Depression in children and adolescents with sickle cell disease. Archives of Pediatrics and Adolescent Medicine, 148, 457-460.

Zill, N. (1985). Behavior problem scales developed from the 1981 Child Health Supplement to the National Health Interview Survey. Washington, DC: Child Trends. 